\title{
Study on the Compilation and Optimization of Construction Organization Design-taking G310 Luoyang City as an example
}

\author{
Huixin Liu ${ }^{1, *}$, Chunxia Zhang ${ }^{1}$ \\ ${ }^{1}$ College of Management Engineering, Zhengzhou University, Science Road, Zhengzhou, China \\ \{630529252, 185877224\}@qq.com
}

Keywords: Construction design, Preparation and analysis, Personnel management, Cost control, Progress control

\begin{abstract}
Reasonable scientific construction organization design is not only the core of the entire project technical guidance, but also a comprehensive embodiment of a construction enterprise's management level. It is important to guarantee that the project be carried out orderly. On the basis of predecessors, the author learned the construction organization design through accessing to literature and specific case studies. Taking the construction design of G310 Luoyang City as an example, the paper analyses the research and construction. The study shows that in the construction of G310 Luoyang City, the construction process of the construction of a pavement is complicated, and the staffing process is lacking in flexibility. These will make the project during construction lack of detailed reference and guidance, affecting the duration and quality of the project. Through the analysis and summary, the author puts forward the strengthening management, the introduction of advanced technology, Luoyang site investigation and environmental considerations, combined with the characteristics of the project by marking the special engineering parts, so that the entire construction organization design and staffing are more mature, in order to achieve the purpose of the construction organization.
\end{abstract}

\section{Introduction}

Into the 21st century this epoch-making key point, all walks of life are in the rapid development. With the economic globalization of the spring, the construction industry is also facing a huge challenge. The reform and opening up brought opportunities but also brought challenges. The reform of the construction industry is imminent. First of all should be the construction organization design and optimization. The success of the construction organization design is the guarantee of the project quality and the project cost. The project quality and the project cost are also a necessary means for the project or a construction enterprise to stand out in the competitive construction industry. With the country's deepening reform of the construction industry, construction projects become the basic industries of the national economy. As the foundation of all construction activities and the core of the construction organization design of the importance can be seen, therefore, combined with the construction conditions, in line with objective laws at the same time to effectively solve practical problems as the goal, to develop a reasonable construction organization design, making the plan objectives Implementation is very necessary and urgent.

Construction organization design is not only an important part of the tender, but also an important component of the construction contract. Before bidding, it is the basis for arguing the tender offer, the construction period, the construction quality, and the commitment and offer to the tender documents (Hu Cheng, 2004). Construction is no longer a simple building in the past, it contains a lot of complex technology. Construction organization design is the guidance of these technologies to ensure the completion of the quality and quantity of the project. A reasonable construction organization design should include engineering construction deployment, construction site management, rational choice of machinery and equipment, and the most important link: cost control. At present, the construction organization design in the preparation and use of the process there are still sets of templates, super, copy cases and other issues, the attitude of the importance of 
this work is not enough, so that the existence of construction organization design into a project To cope with, so that the construction organization design itself on the guiding role of the project gradually disappear.

In the face of the present situation of the construction industry in the construction organization design, this paper takes G310 Luoyang city road reconstruction project pavement construction design as an example. It is hoped that the analysis and research of the case can clarify the importance of the construction organization design work, highlight the role of the strategic deployment and the practical effect of the tactical arrangement, so that the construction enterprises pay more attention to the compilation and optimization of the construction organization design.

The construction of the bid is based on the following five aspects: the purpose of the application of the construction organization design, the conditions of the preparation, the reading object, the content level, the level of responsibility, to understand the compilation characteristics of the construction organization design and summarize the preparation strategy and skill of the tender construction organization design (Dongqing Sun, 2013). With the increasingly fierce competition in the architect market and the rapid development of science and technology, the construction organization has become the basic work of an enterprise, and its technical content is also increasing. This is related to the benefit of an enterprise, corporate image and social reputation (Jiang Ying, 2006).

In order to improve the quality of the implementation of the construction organization design, we should analyze the relationship between the preparation and implementation quality of the construction organization design from the aspects of the preliminary research, the preparation work, the preparation principle, the preparation key and the preparation method of the construction organization design (Xiaobo Duan, 2012). The quality of construction and implementation of construction organization design is an important index to evaluate the effect of construction operation. Only by making it institutionalized and scientifically compiling the construction organization design can we improve the management level of the construction enterprises so that the economic benefits can be improved and the theory can be practically guided (Jianping Tang, 2009).

Optimizing the construction organization design can achieve the purpose of reasonably determining the project cost (Yan Chen, 2010). Reasonable scientific preparation of the technical part of the construction organization design is the project key to strive for the greatest economic benefits, reduce the cost. Construction organization design not only play a role in the construction, but also play the role of improving economic efficiency in the project cost to (Fangqian Jin, 2011). From the relationship between the construction organization design and the project cost, it is of great significance to optimize the construction organization design and reasonably determine the project cost by taking the basic unit price and the project unit price as the entry point (Shaoshuang Zhang, 2003).

In the process of compiling the construction organization design, we should comprehensively study the content preparation and improvement of the construction organization design, and understand in detail the defects in the current construction organization design, and then make improvements on this basis(Juan Wang, 2010).

In this paper, the construction design of L310 Lujiang city road reconstruction project is taken as an example. Through the research and analysis of construction design of G310 Lujiang city road reconstruction project, the defects in the project case are put forward. Through the professional knowledge and access to information, continue to accumulate information, the past valuable cost management case summed up. In view of some deficiencies in the current cost management model, some suggestions and opinions on reform are put forward, and the defects are analyzed and corrected. The purpose is to combine the characteristics of the project, so that the construction organization design more rational and scientific.

\section{Problem Description}

With the construction of large-scale, complex, simply rely on manpower to write construction 
organization design is sometimes difficult to complete, with the computer and related project management software will be very important. And the construction of the project organization design does not fully reflect the use of these advanced technology, making the entire project in the technical application cannot make full use of pre-technical information. At this point, the construction organization's programmatic status becomes passive.

The construction personnel, technical staff in the actual construction process will accumulate the efficiency of management experience and construction experience. However, in the preparation of the construction of the project design, these experiences did not penetrate into the preparation of the construction organization design. So advanced construction technology and management experience to play less than play. In the construction of the project organization design, the designer first to explore the Luoyang City Road reconstruction of the situation to carry out scientific preparation, so as to achieve the transformation project construction goals. However, in the construction process of the construction of the project design process, a large number of duplication of work to make the construction management process becomes complicated, which is very unfavourable to the whole project. In the preparation of construction organization design, engineers need to help the relevant technical staff review and modify. The information or professional gap between the engineers and technical staff will affect the professional, continuity, lack of integrity of the construction organization design, and then affect the quality of the entire project and duration control.

Construction organization design staff is only one-sided construction organization design as a project technical guidance documents, it is not a comprehensive understanding of the construction organization of the key role. The construction organization design is simply to pile up a variety of technical guidance, management system, construction process, apply template. And it is only the various parts of the project analysis, construction methods and processes to elaborate, failed to link the various parts of the project. Pursuing the construction efficiency while ignoring the most important management benefits will affect the overall economic benefits. In the latter part of the construction process, it is possible for the use of technology or blind pursuit of the duration of the increase in costs, resulting in a certain economic losses and even causing settlement in the settlement. Now a lot of construction units of the construction organization design work are generally a fixed number of staff to bear the completion. When the construction organization design staff and the construction site personnel are different, the problem appeared. Site construction personnel, technical staff and the preparation of staff is not the same batch of people will lead to the construction of the actual situation and the file does not match. Compiling staff to prepare the construction organization based on the desk information, and the actual site construction will have a very special case is the desk data cannot be reflected and explained. In this way, the construction organization and the actual situation of the construction site will be out of touch. It directly leads to the construction organization cannot use the design, affecting the duration and quality, resulting in waste.

The construction organization design in the field staff arrangements and the preparation of staff is no coincidence, but the organization is indeed worth considering. Copying template is a common problem in the construction organization design. By directly rewriting the existing project case to achieve the purpose of qualified form, but cannot combine the characteristics of the project, economic factors, personnel and the environment, technical constraints to consider and plan. The organization of the organization did not consider the specific characteristics of the transformation project, did not have its characteristics of the part of the reflected, simple removal of the template will lead to the actual construction of the construction organization design cannot play a guiding role, , The construction organization design and the actual construction of the disengagement will make the construction cannot be effectively controlled, not only cause unnecessary waste, but also makes the project there is a security risk or even become unable to put into use the project.

For the optimization of the design of the construction of the project, the first problem is to find the construction of the pavement engineering design problem, which is the core, but also the entry point, only to seize the existing problems, to its full study, and then find The most sensitive and influential key issues or influencing factors, to study and improve it, can make the construction of 
the project design is the most fundamental optimization.

\section{Optimization of Construction Organization Design}

Construction organization design optimization is the project involved in the construction of the parties: the construction unit, the supervision unit, the construction unit of professional and technical personnel to the construction unit of technology, machinery, resource level, targeted to modify and improve, making the preparation of the construction organization Design documents can better guide the progress of the project, the smooth completion of the cost, duration and quality of the three aspects of the optimal balance to complete the project. In the construction organization design optimization process, the project participants in the construction of all parties must play a role, not only that, reasonable arrangements for staff and institutional settings are also essential. The progress of each project requires the cooperation between the staff and the organization, not too much emphasis on the role of an organization or personnel, but also cannot ignore the role of an organization or personnel, any kind of situation, will So that the project tilt, resulting in irreversible loss.

In the preparation of the construction organization design, we must first select the appropriate personnel, so that engineering and documentation, so that the construction organization of the design of the document to better serve the project. The construction organization design personnel should conduct field visits to understand the actual project, rather than copy the template, completely regardless of the consequences, while the construction organization design should be combined with Luoyang City, the characteristics of the transformation section, the institutions set more accurate, People, for example, when the need to improve the quality of the project, it is bound to affect the total cost, then you need to evaluate the relevant departments of the cost department, whether the capital investment, if the construction organization design is simply a staff set, When the situation occurs, the staff responsibility is unclear, it will lead to the problem is not timely, affecting the duration and even security problems, affecting the quality of the project, clear and reasonable staff arrangements is clear and clear when the problem occurs when the timely allocation of existing resources, Solve the problem.

The layout of the layout of the whole project to show the most direct, not only to consider the actual project situation, in line with local conditions, safe production, economic and reasonable principles of drawing, but also consider the actual conditions of the construction, such as technology, materials, personnel and so on. In modern society, the commonly used computer technology is more and more intelligent layout of the layout, the advanced computer technology applications and layout plan which can not only make the project into three-dimensional graphics, more clear and specific, but also can make the construction staff every Always grasp the construction progress, understand the construction profile, in addition, the application of geographic information system can also further ensure the smooth completion of the project. G310 national road reconstruction project construction organization design in the construction plan can join the computer technology and geographic information system, the construction arrangements into threedimensional specific graphics, so that construction workers and managers to grasp the construction progress and construction of the project to ensure the smooth progress of the project and timely completion.

The role of progress control is reflected in the aspects of site management, quality management, duration management, cost management, safety management, risk management and other aspects of the project, the various aspects of the project are interrelated, interdependent, closely related, any part of the progress of the loss Control will have a certain degree of impact on the entire project. The schedule of the project is the form of the form, the advantages and disadvantages have been analysed in the above, for the specific circumstances of the project, should be in the progress of planning and management to join the construction network schedule and the progress of the preparation of the S-curve. This is often used in the construction of a schedule control of the construction organization method, he can make up for the current schedule of the table in the form of defects, to show the logical relationship between the work, the work of the estimated amount of 
work and the Work of the labour quota, which are calculated by drawing the completion of the. When using the construction network schedule and S-curve, it is necessary to adjust the optimization and optimization in the actual construction process by combining the duration, cost and resources, so as to reflect the actual situation of the reconstruction project, strengthen the engineering dispatching wisdom, The ultimate goal of the opportunity to complete the general requirements of the project, so that the pace of coherence, to ensure the overall interests of the realization. At the same time, but also from the organization and technical aspects of control. First set up a strong project management system, establish a sound job responsibility system, strengthen the front-line organization and leadership command to ensure real-time construction organization plan to achieve.

In the course of the formation of the construction organization design of the municipal engineering, there are some problems in the preparation of the method and the content of the preparation. The reasons for these problems are influenced by various aspects, social reasons and technical reasons. The paper puts forward some suggestions on the improvement of the rectification and improvement, and puts forward some more scientific methods in terms of the construction organization design of the project, hoping to make the construction organization design more perfect, So as to better guide Luoyang City Road reconstruction project.

\section{Conclusions}

Through the previous study, we can clearly recognize that, regardless of which project construction projects, construction organization design is the premise of the project management and the core, its importance is self-evident. In the construction of G310 Luoyang city road reconstruction project construction design, there are two problems in the general construction organization design, but also has its own case, which is more demanding that we grasp the preparation of the scale, strict implementation of standards and norms of the requirements, follow a certain principle to prepare the construction organization design documents. In addition, the preparation of staff attitude, literacy is also an important condition whether the engineering construction organization design can correctly use engineering materials and advanced experience to weave the construction organization. Construction organization design must be combined with the characteristics of the project to achieve the quality, schedule, cost the best balance, so as to achieve the intended purpose of the project.

\section{References}

[1] Dongqing, Sun, 2013. On the construction of structural design and implementation of the improvement, Construction Science and Technology. (13), pp.92-93.

[2] Fangqian, Jin, 2011. Analysis on the Influence of construction organization design on the cost of highway construction project, China New Technologies and Products. (4), pp.71-72.

[3] Guodong, Xu, 2007. Talking about the preparation of construction organization design, Science \& Technology Information. (34), pp.131-132.

[4] Hu, Cheng, 2004. Project Management, Higher Education Press. Beijing, 4th edition.

[5] Juan, Wang, 2010. Shallow talk how to optimize the design of high-Rise buildings construction organization, Journals of Langfang Teachers College. (4), pp.88-89.

[6] Shaoshuang, Zhang, 2003. Cost control and management of construction enterprises, Railway Engineering Cost Management. 18(3), pp.41-44.

[7] Xiaobo, Duan, 2012. Electrical engineering construction organization design and optimization research, Science and Technology Information. 9(23), pp.157-158.

[8] Yan, Chen, 2010. Optimize the construction organization design to reasonably determine the project cost, Cost of Water Conservancy and Hydropower Project. (1), pp.34-36.

[9] Ying, Jiang, 2006. Tender construction organization design preparation skills, Coastal enterprises and technology. (11), pp.78. 